\title{
RESUMO
}

\section{SUPERESTRUTURA JURÍDICA E IMUNIDADE PENAL DA ELITE ECONÔMICA BRASILEIRA NO CRIME DE TRABALHO ESCRAVO}

LEGAL SUPERSTRUCTURE AND CRIMINAL IMMUNITY OF THE BRAZILIAN ECONOMIC ELITE IN THE CRIME OF SLAVE LABOR

SUPERESTRUCTURA JURÍDICA E INMUNIDAD PENAL DE LAÉLITE ECONÓMICA BRASILEÑA EN EL DELITO DEL TRABAJO ESCLAVO
Nonnato Masson Mendes dos Santos ${ }^{1}$ Edith Maria Barbosa Ramos ${ }^{2}$

Artenira da Silva e Silva ${ }^{3}$
O presente artigo problematiza o fenômeno das agências de controle penal acessarem mecanismos despenalizadores quando se trata de condutas criminalizadas cujos autores são em sua maioria membros da elite econômica, se valendo, para tanto, de categorias marxianas e marxistas que compreendem essas agências de controle como parte de uma superestrutura jurídica baseada na infraestrutura econômica garantidora da imunidade penal de determinados grupos que, por regra do sistema, devem ser imunes, posto que a referida engenharia de poder controla os corpos daqueles que podem vir a sublevar o status quo.

\section{PALAVRAS-CHAVE}

Agências de Controle Penal. Seletividade Penal; Poder Judiciário. 


\section{ABSTRACT}

analyzes the application of decriminalizing mechanisms by criminal control institutions to benefit defendants who are part of an economic elite, considering Marxist and Marxian categories, that understand these institutions as part of a legal superstructure based on economic superiority that guarantees the criminal immunity of some groups, controlling, through a system of power, the bodies and minds of who can raise their status quo.

\section{KEYWORDS}

Criminal Control Institutions. Penal Selectivity. Judiciary.

\section{RESUMEN}

Este artículo analiza el fenómeno de las agencias de control penal que acceden a mecanismos de despenalización cuando se trata de conductas criminalizadas cuyos autores son en su mayoría miembros de la élite económica, utilizando, para ese propósito, categorías marxistas y marxistas que entienden estas agencias de control como parte de una superestructura legal basada en la infraestructura económica que garantiza la inmunidad criminal de ciertos grupos, que, como regla del sistema, deben ser inmunes, ya que la ingeniería de energía antes mencionada controla los cuerpos de aquellos que pueden alcanzar el statu quo.

\section{PALABRAS CLAVE}

Agencias de control penal; Selectividad penal; Poder Judicial. 


\section{INTRODUÇ̧̃̃o}

No plano teórico, a Filosofia do Direito de Karl Marx (1818-1883) e as correntes filosóficas dela decorrentes, chamadas de marxistas ou críticas, fundamentam e são a base para a compreensão de como o Direito em geral e o Direito Penal, em especial, se manifestam na sociedade capitalista. 0 marxismo busca compreender a real e concreta manifestação histórica do Direito, desvendando, para tanto, os concretos vínculos entre o Estado, o Direito e a reprodução econômica e social.

As primeiras teorias marxistas avançaram nesse campo, desmistificando uma suposta imparcialidade e neutralidade do direito, ao demonstrarem como este surgiu ligado à mercadoria e ao papel instrumental que cumpre no sentido de garantir os interesses da classe dominante.

É Marx quem denuncia a associação indissolúvel entre o Direito e a estrutura material do capitalismo, pontuando que o Estado e o Direito não se organizam a partir de uma suposta vontade geral - estrutura que não é fundada num contrato social, nem mesmo numa pretensa paz social - que não existe um direito natural, e que a lógica do Direito não está ligada às necessidades de bem comum, nem em verdades jurídicas transcendentes. Marx denuncia que o Estado e o Direito têm sua base e fundamento na história e nas relações de produção, nessa linha

Somente as relações de produção capitalista necessitam - diferentemente de outras na história - de um aparato jurídico que lhe sirva de suporte. 0 escravagismo se funda numa relação de violência direta. 0 capitalismo, no entanto, não vincula o trabalhador ao burguês por conta da violência bruta deste contra aquele. Os vínculos entre ambos se dão por meio de um contrato de trabalho. 0 trabalho assalariado presume o direito. Como qualquer burguês e qualquer trabalhador podem contratar a compra e venda do trabalho, o direito é um instrumento fundamental dessa circulação contínua da mercadoria trabalho. (MASCARO, 2013, p. 296).

, Marx constata que, aprofundando esse raciocínio o direito não é "um conjunto de normas/regras a ser observado por todos” ou que o "justo" seja a-histórico. Não existe uma justiça, e por extensão, um Direito, pensada como substância eterna, fora da história ou das circunstâncias concretas que envolvem a reprodução econômica de um determinado tempo: a justiça é considerada o correto modo de funcionamento de um determinado sistema de exploração.

Piotr Stutchka (2001, p. 59) apresentou a definição do direito como um "sistema de relações que corresponde aos interesses das classes dominantes e salvaguarda estes interesses através da violência organizada". É na política penal que a violência é mais organizada e direcionada. Legitimada por leis, códigos e princípios, seleciona e mantém os membros das camadas mais pobres da sociedade encarcerados numa tentativa, senão de domesticá-los, de ao menos mantê-los à uma distância para que não venham a transgredir as regras do sistema vigente, ameaçando assim o seu funcionamento.

Os juristas marxistas criticam a tradição que compreende o Direito Penal, assim como o Direito em geral, como se fosse uma forma de relações entre "proprietários ideias" ou seja, entre sujeitos egoístas isolados, portadores de um interesse privado autônomo. 
Nesta linha de raciocínio, o Direito Penal é um sistema de regras de organização social e os conceitos que compõem a sua linguagem, a exemplo do "crime”, são institutos ontológicos, preexistentes, provenientes de uma construção ideal que sempre esteve presente na mente humana. Desta forma, as regras se justificam pela sua própria existência, quase como uma naturalidade e o crime se afirma como um valor imutável, ambos inquestionáveis.

O professor Nilo Batista (2011, p. 17) recorda o conceito de “universalismo a-histórico" de Miaille como um dos maiores riscos da aceitação deste dogma:

Na medida em que as ideias constituíssem a matriz da realidade, a história do direito seria autônoma e destacada com respeito ao contexto histórico em que tão direito fora produzido, passando a compor um conjunto de noções universalmente válidas.

O estudo do Direito Penal pelo prisma do método materialista-histórico e pelas circunstâncias concretas em que o grupo se organiza e se reproduz dialeticamente tem o condão de deslegitimar a concepção hegemônica do Direito e do crime. Com um olhar crítico sobre este instituto, é preciso questionar as verdades repetidamente pregadas pelos manuais de direito.

O certo é que não existe um direito natural, pelo contrário, o direito é produto do trabalho e da atividade humana, construído e moldado de acordo com as relações sociais de cada sociedade, ou seja, não é descoberto e nem revelado pelo ser humano, mas sim produzido pelo conjunto.

O discurso crítico da teoria materialista/dialética da pena criminal desvela a natureza real da retribuição penal nas sociedades contemporâneas - que não constitui fenômeno de sobrevivência histórica de vingança privada, nem a expiação ou de compensação de culpabilidade. Desse modo,

A teoria criminológica materialista/dialética mostra a emergência histórica da retribuição equivalente como fenômeno sócio-estrutural específico das sociedades capitalistas: a função de retribuição equivalente da pena criminal corresponde aos fundamentos materiais e ideológicos das sociedades fundadas na relação capital/trabalho assalariado, porque existe como forma de equivalência jurídica fundada nas relações de produção das sociedades capitalistas contemporâneas. (SANTOS, 2005, p. 19).

Se o Direito não é algo dado e sim construído pela sociedade, há de se perguntar quem é a parcela da sociedade que efetivamente o constrói, e ainda, quais os interesses, a posição, os objetivos desta parcela.

\section{SELETIVIDADE [E IMUNIDADE] PENAL DE CLASSE E ÉTNICA}

A obra de Ruche e Kirchheimer Punição e Estrutura Social é o primeiro trabalho marxista a analisar a questão criminal historicamente, associando condições sociais, mercados de trabalho e sistemas penais. 
Ele [Rusche] demonstrou o caráter histórico dos sistemas penais através das suas diferenças em relação às diferentes fases do processo de acumulação do capital, analisando as mudanças ocorridas no processo de longa duração entre os séculos XV e XX (esta última complementada por Kircheheimer após o suicídio de Rusche. (MALAGUTI, 2014, p. 91).

A transição para o sistema capitalista, ocorrida entre os séculos XIV e XV, foi marcada pela intensificação de conflitos sociais na região norte da Itália e norte da Alemanha, levando a um processo de criação de leis penais mais severas, dirigidas às classes menos favorecidas. 0 crescimento da criminalidade entre os setores do proletariado, em especial nas grandes cidades, fez com que as classes dirigentes buscassem novas formas de administração mais efetiva da lei criminal.

Assim, o sistema de penas, marcado pela punição corporal e fianças permaneceu, contudo, a aplicação da lei era feita de acordo com a classe social do condenado (RUSCHE, 2004, p. 31). A maioria dos selecionados pela lei penal pertenciam às classes mais baixas, de modo que o termo "vilão", originariamente aplicado aos membros de determinada classe social, (aqueles que viviam em vilas), passou a indicar um julgamento de inferioridade moral (RUSCHE, 2004, p. 32).

Segundo Rusche (2004, p. 32), quando o crime de danos à propriedade era praticado por membro de classes dominantes, a concepção legal era mais flexível:

Um conjunto de leis e práticas judiciais tão antiga quanto a Clagspiegel estabelece que devem ser feitas negociações no sentido de se chegar a um acordo em casos criminais, inclusive para aqueles que preveem pena de morte. A concepção de feudo oferecia uma cobertura legal para quebras da paz ou para o roubo das classes dominantes. Qualquer que seja a discordância que exista hoje em dia acerca dos campos de aplicação dos artigos 128 e 129 do Código Criminal de Carlos V, contemplando a litigiosidade feudal e a rebelião, é certo que o direito propiciou um vasto campo de imunidade para atos que seriam punidos severamente se praticados por membros de classes inferiores. (RUSCHE, 2004, p. 32)

Uma das principais preocupações da burguesia urbana que emergia era a criação de uma lei específica para combater delitos contra a propriedade. Assim, onde fosse possível o monopólio da legislação e jurisdição, a burguesia insistiu em tal ponto com bastante ênfase. Quanto mais pobres as massas, mais severos os castigos para dissuadi-los à prática de delitos (RUSCHE, 2004, p. 32).

A legislação vigente era flagrantemente severa com as classes proletárias. Nos casos em que 0 procedimento criminal era igual para todos os estados e classes, apareciam com frequência procedimentos especiais que afetam especificamente as classes subalternas. Assim, a simplificação de procedimentos, por exemplo, nos casos de prisão em flagrante delito, permitia o isolamento de uma determinada classe de «foras da lei» para os quais as previsões legais, a citar a gravidade do delito, não poderiam ser aplicadas de forma plena (RUSCHE, 2004, p. 37).

A reconstrução histórica da prisão realizada por Rusche e Kirchheimer, esclarece a relação crime e formação econômico social, levando «à inserção do fenômeno criminoso na esfera da produção (e não, apenas, na esfera de circulação): as relações de produção e as questões de poder (econômico e político)" (CIRINO, 2002, p. 3). 
Assim, o principal foco do marxismo no que se relaciona à criminalidade é a crítica estabelecida ao funcionalismo do pensamento criminal:

A lei penal nada mais é do que uma estrutura (também designada superestrutura) dependente do sistema de produção (infraestrutura ou base econômica). 0 direito, ao contrário do que afirmam os funcionalistas, não é uma ciência, mas sim uma ideologia que só será entendida mediante uma análise sistêmica denominada método histórico-dialético. O homem, por sua vez, não tem o livre-arbítrio que lhe atribuem, pois está submetido a um vetor econômico que lhe é insuperável e que acaba por produzir não só o crime em particular, mas também a criminalidade como um fenômeno mais global, com as feições patrimoniais e econômicas que todos conhecem. (SHECAIRA, 2013, p. 282-283).

Em outras palavras, "o direito penal vem ao mundo (ou seja, é legislado) para cumprir funções específicas dentro de e para uma sociedade que concretamente se organizou de determinada maneira" (BATISTA, 2011, p. 19). Sob a ótica da criminologia crítica, a criminalidade se manifesta, em verdade, como uma posição social atribuída aos sujeitos, cuja construção se baseia na hierarquia de interesses socioeconômicos e na desigualdade social. Desta forma, emerge um direito penal seletivo, separando cidadãos impunes daqueles que sequer alçam a condição de cidadania.

0 processo de criminalização se inicia a partir da definição dos tipos penais pelo legislador, passando pela aplicação das leis criadas pelas agências de execução penal ao caso concreto e se encerra na execução das penas. Tal organização reafirma a existência de um aparato estatal punitivo que se desenvolve de maneira seletiva. Referida preposição parte da ideia de que o Direito Penal é verdadeiro instrumento de repressão das consequências de desigualdades sociais que implicam em injustiça social (GUIMARÃES, 2010, p. 29).

A criminalização primária (elaboração de normas penais pelo legislador) determina quais comportamentos sociais devem ser tidos como criminosos em concordância com os interesses representados pela classe dominante, sendo que a criminalização secundária (efetiva aplicação da lei penal) desempenha outra importante função do Direito Penal: a aplicação da lei em abstrato sobre comportamentos inerentes às camadas mais pobres da sociedade, desviando o foco dos delitos que são praticados pelos membros da elite, de modo que estes restam imunizados em face do Sistema Penal (GUIMARÃES, 2010, p. 30).

Assim, o que a criminologia crítica questiona são os motivos pelos quais, entre tantas pessoas que cometem delitos, somente algumas sofrem a intervenção do sistema penal. E ainda, quais os motivos para que tantos outros comportamentos nocivos à sociedade, quando praticados pelas classes favorecidas, não sejam tipificados como crimes ou, quando o são, a maioria esmagadora dos que o praticam jamais são alcançados pelas malhas do Direito Penal?

Alessandro Baratta (2011, p. 165), ao tratar da seletividade do Direito Penal, explica que:

No que tange à seleção dos bens protegidos e dos comportamentos lesivos, o caráter fragmentário do direito penal perde a ingênua justificativa baseada sobre a natureza das coisas ou sobre a idoneidade técnica de certas matérias, e não de outras, para ser objeto 
do controle penal. Estas justificações são uma ideologia que cobre o fato de que o direito penal tende a privilegiar os interesses das classes dominantes, e a imunizar do processo de criminalização comportamentos socialmente danosos típicos dos indivíduos a ela pertencentes, e ligados funcionalmente à existência da acumulação capitalista, e tende a dirigir o processo de criminalização, principalmente, para formas de desvio típicas das classes subalternas (BARATTA, 2011, p. 165).

A seletividade ocorre não somente no momento da escolha dos comportamentos que serão descritos na lei e na intensidade da ameaça penal para quem os pratica, mas sim com a própria formulação técnica dos tipos legais. Quando se trata de tipos dirigidos aos indivíduos pertencentes às classes menos favorecidas e que se contrapõe às relações de produção (em especial ao direito de propriedade) e distribuição capitalista, os tipos penais formam uma rede fina, enquanto essa rede se apresenta de forma mais larga quando os tipos penais referem-se à criminalidade econômica e outras que pertencem às classes no poder (BARATTA, 2001, p. 165).

\section{FAZENDEIROS E PEÕES: CLASSES E “RAÇAS” EM LUTA}

O artigo 149 do Código Penal Brasileiro de 1940, com a nova redação dada pela Lei nº 10.803/2003, tipifica a conduta de trabalho escravo contemporâneo, elencando quatro modalidades: trabalhos forçados, jornada exaustiva, trabalho degradante ou servidão por dívidas, preceituando, ainda, que incorre nas mesmas penas quem cercear a liberdade de trabalhadores, mantendo vigilância ostensiva ou qualquer quem utiliza qualquer meio com o fim de reter o trabalhador no local de trabalho. É prevista punição de reclusão de dois a oito anos e multa, que será aumentada quando a vítima for criança ou adolescente, ou o crime for cometido por motivo de preconceito de raça, cor, etnia, religião ou origem.

Segundo estimativas da Comissão Pastoral da Terra (CPT), existem no Brasil, hoje, mais de 25 mil pessoas submetidas à condição análoga a de escravo, sendo que o Estado do Maranhão ocupa as primeiras colocações em número de fazendas flagradas com trabalho escravo (FILHO, 2011, p. 19). Contudo, poucos são os fazendeiros que respondem a ação penal na justiça, sendo que somente $40 \%$ dos relatórios de fiscalização do país que concluem pela existência de trabalho escravo resultaram em propositura de ação penal. No maranhão o índice é de cerca de 25\% (FILHO, 2011, p. 154).

Apesar das primeiras fiscalizações no Brasil terem ocorrido em 1996, pouquíssimas são as condenações penais decorrentes daquelas. Levantamento feito pelo Centro de Defesa da Vida e dos Direitos Humanos Carmen Bascaran conclui que no Maranhão, até janeiro de 2011, havia apenas quatro fazendeiros condenados criminalmente, sendo que em duas dessas condenações, de primeiro grau e sem trânsito em julgado, a pena foi convertida em prestação de serviços à comunidade (FILHO, 2011, p. 159).

A miséria, produzida por um sistema de concentração de renda, é condição propícia para a escravidão, criando vários personagens: os peões “escravizados", o patrão “proprietários de terras" e o gato “aliciador", sendo estas três figuras importantes nesse processo (FILHO, 2011, p. 21). 
É possível ainda identificar o perfil geral dos escravocratas contemporâneos. É evidente a concentração de terras em suas mãos, o que demonstra que em sua maioria são membros da elite econômica nacional, vindos das regiões Sudeste e Centro-Oeste do país. Quando são flagrados praticando o crime, agem como se não cometessem ilícito algum. Vários deles dizem que a situação na qual os trabalhadores são encontrados nas fazendas é comum e faz parte da cultura da região, numa tentativa de construir um imaginário de que a situação de exploração apresentada é natural e não constitui ilegalidade (FILHO, 2011, p. 210).

Nesse contexto, a conduta criminalizada no art. 149 do Código Penal Brasileiro inverteria a lógica da denunciada seletividade do sistema penal, vez que coloca no banco dos réus setores da sociedade que não fazem parte da clientela da justiça penal.

Dados fornecidos pela Organização Internacional do Trabalho (2011) traçam o perfil dos empregadores e dos trabalhadores nas fazendas flagradas com trabalho escravo. Entre os empregadores predominam os brancos, a maioria nascidos na região Sudeste, com curso superior completo, sendo a formação universitária voltada principalmente para administração de empresas e para atividades rurais.

Para muitos, não apenas seus pais, mas seus antepassados estavam vinculados às atividades agropecuárias e ao processo de ocupação do território e criação de cidades e municípios, constituindo-se assim uma espécie de elite patrimonialista que acumula recursos e alimenta poderes. Segundo um dos empresários, 'mexer com a terra está no sangue. (OIT, 2011, p. 129).

Segundo dados do Atlas Político-Jurídico do Trabalho Escravo Contemporâneo no Maranhão (2011), a maioria dos escravocratas possuem grandes propriedades de terra, de tamanho superior a 2 mil hectares (alguns com mais de 20 mil hectares), São membros da elite econômica do país e mantém relação com a política. Em contrapartida, os trabalhadores-vítimas são, em sua maioria, afrodescendentes (índice superior a 80\%), com escolaridade extremamente baixa, sendo a maior parte maranhenses (41,2\%) (OIT, 2011, p. 57).

Exemplar é o interrogatório de um fazendeiro acusado e processado pela prática de trabalho escravo, chamando a atenção sua afirmação de que "seu lazer é o trabalho", frase que sintetiza a tentativa de demonstrar que é um homem adaptado ao sistema que privilegia simbolicamente "homens que trabalhem" e desprivilegia "vagabundos", “vadios”, “mendigos”:

Tenho uma empresa em Lagarto, Maratá copos descartáveis, uma em Itaporanga, Maratá Alimentos, e outra em Estância, Maratá Suco do Nordeste. Tem algumas propriedades no município de Itaporanga, uma faculdade em Lagarto e a Fundação José Augusto Vieira com aproximadamente 400 crianças. No Maranhão tem umas 20 (vinte) fazendas, inclusive a propriedade objeto da denúncia possui 22.500 hectares, possui uma escola para os filhos dos trabalhadores da fazenda e para a população do povoado vizinho". (Processo no $2005.37 .00 .006497-5,1^{\text {a }}$ Vara da Justiça Federal da Seção Judiciária do Estado do Maranhão, fls. 287)

Que não administra a fazenda, sendo administradores: o filho, Ricardo, o gerente Paulo e o gerente geral Antenor. Ricardo mora em São Luís e administra todas as fazendas. 
Antenor o gerente geral vai a todas as fazendas e faz levantamentos e conversa com os gerentes das fazendas, Paulo, gerente da fazenda mora na fazenda e administra toda a fazenda, quando as questões fogem de sua alçada liga para o Antenor. Não conhece o gato Anão. Que o sistema que se dá na fazenda consiste na empreitada contratada diretamente pelo gerente da fazenda, sr. Paulo, que contrata o empreiteiro terceirizando a mão de obra diretamente ao empreiteiro por hectare, linha, tarefa. (Processo nº 2005.37.00.006497-5,

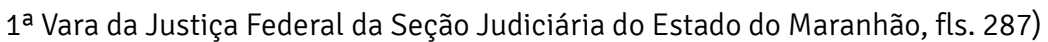

As informações acima expostas nos levam a concluir que o delito de submeter outrem à condição análoga a de escravo faz parte do conjunto de crimes afetos à elite social, o que, nos termos já expostos da criminologia crítica, culmina no reduzido (quase nulo) número de condenações penais aos fazendeiros escravocratas, posto que fazem parte dos “imunizados" frente ao Direito Penal.

\section{PODER JUDICIÁRIO ENQUANTO SUPERESTRUTURA DE (DES)CONTROLE PENAL}

Não é difícil chegar à conclusão de que o atual sistema de justiça favorece o fazendeiro. No Estado do Maranhão, alguns fazendeiros já estiveram presos por algum tempo, em alguns casos dignos de nota como exceções, o que só confirma o raciocínio de que a regra geral é a impunidade. Contudo, nenhum dos casos de prisão ocorreram para cumprir pena após a condenação, já que ocorreram sempre em prisão cautelar, antes do julgamento (FILHO, 2011, p. 148).

A lei penal sempre foi formulada pela classe dirigente. Sendo assim, o que define, na maioria das vezes, aquilo que deve ser considerado comportamento delitivo são os interesses representados por aqueles que elaboram as leis. Pode-se afirmar, portanto, que o sistema foi pensado antes para imunizar determinadas pessoas e comportamentos do que propriamente para proteger a sociedade (GUIMARÃES, 2010, p. 33.).

A concepção de Direito, ainda que revestida de uma aura de neutralidade e imparcialidade, resulta de uma sociedade de desiguais e, em primeira instância, se configura como elemento fundamental para a manutenção desta. Isto fica mais evidente quando analisamos os limites da concepção e da utilização do Direito na sociedade capitalista, que o revelam como resultado da evolução do atual modo de produção.

As primeiras teorias marxistas do direito avançaram nesse campo, desmistificando a "imparcialidade e a neutralidade do direito", ao demonstrarem como este surgiu ligado a mercadoria e o papel instrumental que cumpre no sentido de garantir os interesses da classe dominante.

Nesse sentido, Stutcka demonstra que o direito não pode ser considerado como um fenômeno neutro ou isolado do contexto social em que está inserido, já que é expressão da luta de classes, sendo, portanto, expressão das relações sociais da classe dominante, sustentando-se na força organizada dessa mesma classe (MASCARO, 2013, p. 462).

O direito, para Pachukanis, não é apenas um aparato a serviço da burguesia, ele está intimamente atrelado à própria lógica do capital (MASCARO, 2013, p. 475). O Direito Penal é parte da superestrutura jurídica e a jurisdição penal é uma arma na luta de classes. Nesse contexto, não há o que se falar 
em tribunal imparcial, posto que se manifesta na prática como uma organização direta da violência de classe, cujas ações são conduzidas unicamente por considerações de oportunidade política.

A política penal tem um conteúdo de defesa social (ou mais precisamente de defesa da classe dominante), dando às abstrações jurídicas do delito e da pena a sua realidade concreta e conferem-lhe um significado prático no quadro da sociedade burguesa (PACHUKANIS, 1988, p. 126).

0 que se observa nos processos que envolvem trabalho escravo é uma absorção do magistrado do discurso da defesa dos fazendeiros. Pode-se atribuir esse fator a uma possível influência dos magistrados pelos sujeitos que fazem parte no processo. Nesse ponto cabe notar a categoria das testemunhas de defesa. Cita-se como exemplo o caso da Fazenda Floresta, localizada no Estado do Tocantins. Entre as testemunhas de defesa figuravam um magistrado substituto da Justiça Federal do Tocantins, um delegado de polícia e empresários locais. Portando, havia uma identidade de classe entre o juiz e esses sujeitos (ANDRADE, 2013, p. 125).

O magistrado tem um conceito de trabalho degradante a partir de sua classe social e se fecha nela. É a análise de um conceito limitado ao seu grupo social. É a defesa de seu grupo. Alguns magistrados chegam até a absorver o discurso de que o crime seria praticado por ser um "traço cultural da região" o que poderia ser caso de despenalização com a absolvição (ANDRADE, 2013, p. 125).

O Direito Penal não é democrático, pois não cumpre as funções prometidas, entre as quais a de segurança jurídica, via princípios da legalidade e da igualdade. Vários membros do Ministério Público acreditam em seu discurso e o aplicam automática e acriticamente atentando, portanto, contra o Estado Democrático. (GUIMARÃES, 2010, p. 255).

[...] no contexto em que está situado espaço e temporalmente no Brasil, o Ministério Público não está, no âmbito punitivo, cumprindo com a função a ele atribuída pela Constituição Federal, em seu artigo 127, mais claramente: a instituição ministerial não está defendendo o regime democrático quando exerce suas funções na esfera criminal. (GUIMARÃES, 2010, p. 261).

No sistema capitalista, as relações sociais e econômicas sempre se baseiam no princípio da retribuição equivalente em todos os níveis da vida social, numa relação de troca de mercadorias mensuráveis por um valor: sendo a expressão máxima a troca do trabalho/tempo pelo salário (equivalente ao tempo). Ora, as formas jurídicas da formação social capitalista instituem a retribuição equivalente no âmbito da responsabilidade penal, esta retribuição é instituída sob forma de pena privativa de liberdade, como valor de troca do crime medido pelo tempo de liberdade suprimida.

A importância da teoria de Pachukanis está em situar a retribuição equivalente no fecho da transição histórica do "sujeito zoológico" da vingança de sangue para o "sujeito jurídico" da pena proporcional: troca igual exclui a vingança posterior, primeiro pelo talião e mais tarde pela composição e, finalmente, se consolida como retribuição equivalente medida pelo tempo de liberdade suprimida - conforme o critério de valor da sociedade capitalista. (SANTOS, 2005, p. 22). 
A justiça penal se manifesta como um meio de que dispõem os detentores do poder para reprimir, oprimindo as classes exploradas, classificando a jurisdição criminal do Estado burguês como: o terror da classe organizada. O Direito Penal no sistema capitalista constitui-se numa forma de troca de equivalentes, interação que não ocorre entre mercadores independentes e iguais que se encontram, mas entre membros de classes sociais de interesses antagônicos e constitui-se em uma arma das elites na luta de classes.

Quanto mais aguda e encarniçada se torna esta luta, tanto mais a dominação de classe encontra dificuldades em se efetivar no interior da forma jurídica. Neste caso, o tribunal "imparcial”, com as suas garantias jurídicas, é rechaçado, e toma frente uma organização direta da violência de classe, cujas ações são conduzidas unicamente por considerações de oportunidade política. (PACHUKANIS, 1988, p. 126).

Na prática forense, a fórmula apresentada pelo sistema penal apresenta o representante do Ministério Público em sua acusação, reclamando um preço "alto”, ou seja, uma pena o mais severa possível; o acusado em sua defesa faz a "pechincha”, solicita indulgência, "uma redução" ou "atenuação" e o juiz se sentencia "em toda a equidade", estabelecendo um "valor-tempo" equivalente.

A forma de equivalência se consolida no sistema capitalista que tem como base o nivelamento de trocas medida por valores, de modo que o processo penal assume o caráter de garantidor de um contrato comercial. A alternativa apresentada pelo sistema é obrigar o agente transgressor da norma a pagar na moeda que tem (algum tempo de privação de liberdade). Assim, as relações entre o Estado e o agente transgressor da norma encontram-se inteiramente inseridas no quadro de um leal negócio comercial. É justamente nisso que consistem as garantias do processo penal.

A retribuição penal está, portanto, ligada à noção de valor da mercadoria, sendo determinada pela quantidade de trabalho social necessário para a sua produção: o tempo médio de dispêndio de energia produtiva.

A definição de pena como 'forma salário da privação de liberdade', baseada no 'valor de troca de tempo' formulada por Foucault (e, antes dele, por Rushe e Kirchheimer), também aparece (mais claramente) em Pachukanis, ao indicar a "medida de tempo" como critério comum para determinar o valor do trabalho (na economia) e a privação da liberdade (no Direito). (SANTOS, 2005, p. 22).

A analogia da pena com a mercadoria revela a dimensão de valor de uso e o valor de troca da pena; o valor de uso da pena criminal consiste nas funções de prevenção (neutralização do condenado, correção do condenado, intimidação de criminosos potenciais, afirmação da validade da norma, ou como afirmação dos valores comunitários), no sentido de funções utilitárias atribuídas pela ideologia penal e o valor de troca da pena é medido pelo tempo de liberdade suprimida do condenado, na preservação da ordem social fundada na relação capital/trabalho assalariado das sociedades contemporâneas.

O valor de uso da pena constitui utilidade atribuída, cujas funções reais de garantia das condições fundamentais da sociedade capitalista, são eficazes: garantem a separação força de trabalho/meios de produção, sobre a qual assenta o modo de produção fundado na contradição capital/trabalho as- 
salariado - ou seja, o valor de uso atribuído à pena, inútil do ponto de vista das funções declaradas do sistema penal, é útil do ponto de vista das funções políticas reais da pena, precisamente porque a desigualdade social e a opressão de classe do capitalismo é garantida pelo discurso penal da correção/neutralização individual e da intimidação/reforço da fidelidade jurídica do povo.

As agências executivas do sistema - Polícia, Ministério Público, Magistratura e Órgãos de Execução Penal - são chamadas a operacionalizar tudo aquilo que é previsto abstratamente na lei penal, ou seja, concretizar os anseios do controle social, via Direito Penal, elaborados pelo legislador. A isso, chama-se criminalização secundária.

É exatamente nesse ponto que ocorre a ruptura entre o que foi elaborado e desejado e aquilo que na realidade pode ser executado.

Na verdade, constata-se que a pena privativa de liberdade é aplicada como forma de contenção das camadas excluídas pelo poder constituído para a manutenção de seus próprios privilégios, portanto, de maneira direcionada, seletiva e excludente. Esta é a função verdadeiramente perseguida pelo sistema quando da utilização da pena. Ademais quando da aplicação da lei penal, elaborada, como já dito, para proteger interesses de determinados estratos sociais, constata-se que, na maioria das vezes, esta só é aplicada contra determinada classe de pessoas, o que é empiricamente constatado quando de uma vistoria em qualquer delegacia ou qualquer delegacia ou presídio brasileiro. Não pode ser mera coincidência que apenas pessoas excluídas façam parte da clientela prisional. (GUIMARÃES, 2010, p. 209).

O professor e promotor de justiça Cláudio Guimarães (2010, p. 209) sentencia: “as prisões brasileiras tem uma clientela específica”, para então criticar o papel desempenhado pelos membros do Ministério público, instituição da qual faz parte.

Essa é a realidade que parece não ser percebida por muitos dos que compõem o órgão incumbido de defender o Estado Democrático.

Os membros do Ministério Público, de maneira geral, não se dão conta das interferências da ideologia dominante no agir, das agências de controle do sistema penal, absorvendo, de maneira acrítica, o saber elaborado para legitimar as flagrantes injustiças por ele produzidas e, de boa fé - na maioria da vezes -, no exercício de suas atribuições, acabam por comprometer o exercício de seu mister constitucionalidade defensor da democracia. (GUIMARÃES, 2010, p. 212)

[...] infere-se que o Ministério Público ainda não se deu conta de que o Direito Penal não é o melhor instrumento para a solução dos conflitos sociais. Ao aplicá-lo de forma automática e acrítica, estão os promotores e procuradores se colocando a serviço dos interesses daqueles que detêm o poder, trabalhando acordes com a ideologia dominante e, portanto, servindo de instrumento que garante privilégios e obstaculiza as possibilidades de implementação da democracia no Brasil. (GUIMARÃES, 2010, p. 253).

Este quadro apontado pelo autor em relação ao Ministério Público, enquanto agência de controle penal, se repete na atuação da Polícia, do Judiciário e dos órgãos de execução penal. Em que 
pese a gravidade dos crimes praticados pela elite econômica, se comparados a outros tipos penais, compara-se a pena prevista ao crime de submeter outrem à condição análoga à de escravo ao crime de sequestro e cárcere privado, semanticamente similares, percebe-se que a norma penal é bem mais branda no que se refere ao primeiro. Ainda que haja previsão legal para alguns delitos das elites, as ínfimas condenações confirmam a existência de um sistema penal seletivo, não sendo os fazendeiros escravocratas a clientela do Direito Penal.

Desta forma é que registramos uma carta escrita por uma vítima do trabalho escravo, que na década de 1980, que conseguiu fugir e denunciar o fato às autoridades, muito embora os agressores não tenham sido punidos. A carta é endereçada a um agente de uma entidade católica que lhe dera apoio e foi escrita alguns anos depois da denúncia.

Sofrido, mas estou bem de cabeça erguida, lutando pra vida. Não quero falar de mágoa nem de dores, mas fugi da justiça injusta da impunidade punidora [...]. A gente não se sente contente, sabendo que tudo isso é o vai e vem da vida (REZENDE, 2001, p. 285).

\section{CONSIDERAÇÕES FINAIS}

A política criminal adotada pelo sistema capitalista se reveste de uma verdadeira guerra aos pobres em todo o mundo ocidental, com o fim de deixá-los dóceis e disciplinados, conformados em sua situação de oprimidos. A base teórica desse raciocínio é encontrada nos escritos de Karl Marx e dos primeiros marxistas que procuraram compreender a real e concreta manifestação histórica do direito, os vínculos entre o Estado, o direito e a reprodução econômica e social.

0 aprofundamento do estudo e pesquisa em uma "criminologia marxista" auxilia na compreensão mais concreta, não apenas relativa à uma "guerra aos pobres" (clientela majoritária do Direito Penal "comum"), mas também, acerca da relação e localização dessa na luta de classes do tratamento penal que se dá aos crimes "políticos" - revelados na impunidade dos crimes de colarinho branco (entre os quais o de trabalho escravo), revelando o alto grau de ilegitimidade do Estado enquanto "contrato social" entre "iguais".

\section{REFERÊNCIAS}

BATISTA, Nilo. Introdução crítica ao direito penal brasileiro. 12. ed. Rio de Janeiro: Revan, 2011.

CIRINO DOS SANTOS, Juarez. A criminologia radical. Rio de Janeiro: Ed. Forense, 2002.

CIRINO DOS SANTOS, Juarez. Teoria da pena: fundamentos políticos e aplicação judicial. Curitiba: Lumen Juris, 2005. 
GUIMARÃES, Cláudio Alberto Gabriel. Constituição, Ministério Público e Direito Penal: a defesa do estado democrático no âmbito punitivo. Rio de Janeiro: Editora Revan, 2010.

MALAGUTI BATISTA, Vera. Introdução crítica à criminologia brasileira. Rio de Janeiro: Editora Revan, 2012.

MASCARO, Alysson L. Filosofia do direito. 3. ed. São Paulo: Atlas, 2013.

NAVES, Márcio Bilharino. Marxismo e direito: um estudo sobre Pachukanis. São Paulo: Boitempo, 2000.

PACHUKANIS, E. B. Teoria geral do direito e marxismo. São Paulo: Acadêmica, 1988.

RUSCHE, George; KIRCHHEIMER, Otto. Punição e estrutura social. 2. ed. Rio de Janeiro: Revan, 2004.

SHECAIRA, Sérgio Salomão. Criminologia. 5. ed. São Paulo: Revista dos Tribunais, 2013.

STUTCHKA, Piotr. Direito de classe e revolução socialista. 2. ed. São Paulo: Instituto José Luís e Rosa Sundermann, 2001.

STUTCHKA, Piotr. Direito e luta de classes: Teoria Geral do Direito. São Paulo: Acadêmica, 1988.

ZAFFARONI, Eugenio R.; PIERANGELI, José H. Manual de direito penal brasileiro: Parte Geral. 4. ed. São Paulo: Revista dos Tribunais, 2002. 
1 Mestre em Direito e Instituições do Sistema de JustiçaUFMA (2017); Especialista em Direito Penal e Direito Processual Penal pela Faculdade Estácio de São Luís (2015) e em Direitos Humanos e Mediação de Conflitos - UEMA (2014); Bacharel em Direito - UFMA (1998); Advogado criminalista e professor universitário. E-mail: pretomasson@yahoo.com.br

2 Doutora em Políticas Públicas pela Universidade Federal do Maranhão; Pós-Doutora em Direito Sanitário pela Fundação Oswaldo Cruz - FIOCRUZ/Brasília/DF; Mestre em Direito pela Universidade Federal de Minas Gerais; Graduada em Direito pela Universidade Federal do Maranhão; Professora do Departamento de Direito da Universidade Federal do Maranhão; Professora e Vice-Coordenadora do Mestrado em Direito e Instituições do Sistema de Justiça da Universidade Federal do Maranhão; Coordenadora do Núcleo de Estudos em Direito Sanitário - NEDISA/UFMA; Professora e Pesquisadora da Universidade do CEUMA - UNICEUMA; Bolsista - BEPP/FAPEMA (Bolsa de Estímulo à Produtividade em Pesquisa - Edital $n^{\circ}$ 007/2018 - Produtividade); Membro Convidado da Rede Ibero-Americana de Direito Sanitário e da Associação Lusófona de Direito da Saúde - ALDIS; Presidente da Comissão de Bioética e Biodireito do Conselho Seccional da OAB/MA; Tem experiência na área de Direito, com ênfase em Sociologia do Direito, Direito Constitucional e Direito Administrativo, atuando principalmente nos temas: direito sanitário, propriedade intelectual, inovação e políticas públicas. E-mail: edithmbramos@gmail.com

3 Doutora em Saúde Coletiva pela Universidade Federal da Bahia - UFBA (2005); Pós- doutoranda em Direitos Humanos na Universidade Federal do Pará ( 2019) e em Psicologia e Educação pela Universidade do Porto- Portugal (2014); Mestre em Saúde e Ambiente pela Universidade Federal do Maranhão (2000); Graduada pela Psicologia pela Pontifícia Universidade Católica de São Paulo; Professora e pesquisadora associada da Universidade Federal do Maranhão e consultora em violência doméstica e proteção de direitos infanto-juvenis; Atua predominantemente no Programa de Pós-graduação de Direito e Instituições do Sistema de Justiça - UFMA; Professora convidada de Universidades portuguesas e espanholas; Autora de diversos livros e artigos Qualis A e B em suas temáticas de pesquisa; Consultora e capacitadora em Violência Doméstica, Metodologia das Ciências Sociais e em Garantia de Direitos Fundamentais de Grupos Vulneráveis; Linhas de Pesquisa: efetividade do Sistema de Justiça na garantia dos Direitos Fundamentais de Grupos Vulneráveis, Violência Doméstica e Social; Objetos de estudo atuais: violência doméstica ou intrafamiliar, alienação parental, bioética, biopoder, masculinidades, feminilidades, liberdade religiosa, violência institucional, violência por poderes e segurança jurídica. E-mail: pretomasson@yahoo.com.br

Recebido em: 22 de Outubro de 2019

Avaliado em: 13 de Março de 2020

Aceito em: 13 de Março de 2020

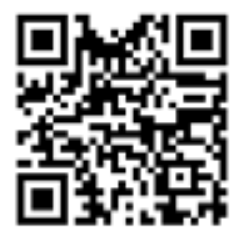

A autenticidade desse artigo pode ser conferida no site https://periodicos. set.edu.br

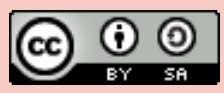

Este artigo é licenciado na modalidade acesso abertosob a Atribuição-Compartilhalgual CC BY-SA

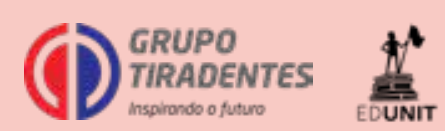

